\title{
Fabrication of Photoactive Electrospun Cellulose Acetate Nanofibers for Antibacterial Applications
}

\author{
Tomasz Czapka ${ }^{1, * \mathbb{D}}$, Angelika Winkler ${ }^{1}$, Irena Maliszewska ${ }^{2} \mathbb{D}$ and Ryszard Kacprzyk ${ }^{1}$ \\ 1 Department of Electrical Engineering Fundamentals, Wroclaw University of Science and Technology, \\ Wybrzeże Wyspiańskiego 27, 50-370 Wrocław, Poland; angelika.winkler@pwr.edu.pl (A.W.); \\ ryszard.kacprzyk@pwr.edu.pl (R.K.) \\ 2 Department of Organic and Medicinal Chemistry, Wroclaw University of Science and Technology, \\ Wybrzeże Wyspiańskiego 27, 50-370 Wrocław, Poland; irena.helena.maliszewska@pwr.edu.pl \\ * Correspondence: tomasz.czapka@pwr.edu.pl
}

check for updates

Citation: Czapka, T.; Winkler, A.; Maliszewska, I.; Kacprzyk, R. Fabrication of Photoactive Electrospun Cellulose Acetate Nanofibers for Antibacterial Applications. Energies 2021, 14, 2598. https://doi.org/10.3390/en14092598

Academic Editor: Bashir A. Arima

Received: 31 March 2021

Accepted: 29 April 2021

Published: 1 May 2021

Publisher's Note: MDPI stays neutral with regard to jurisdictional claims in published maps and institutional affiliations.

Copyright: (C) 2021 by the authors. Licensee MDPI, Basel, Switzerland. This article is an open access article distributed under the terms and conditions of the Creative Commons Attribution (CC BY) license (https:/ / creativecommons.org/licenses/by/ $4.0 /)$.

\begin{abstract}
The aim of the study was to investigate the process of electrostatic fabrication of cellulose acetate (CA) nanofibers containing methylene blue (MB) as a photosensitizer. The electrical, physicochemical, and biocidal properties of the prepared material were given. CA nanofibers were prepared by electrospinning method using a solvent mixture of acetone and distilled water $\left(9: 1 \mathrm{vv}^{-1}\right)$ and different concentrations of CA (i.e., 10-21\%). Additionally, methylene blue was implemented into the polymer solution with a CA concentration of $17 \%$ to obtain fibers with photo-bactericidal properties. Pure electrospun CA fibers were more uniform than fibers with MB (i.e., ribbon shape). Fiber diameters did not exceed $900 \mathrm{~nm}$ for the tested polymer solutions and flow rate below $1.0 \mathrm{~mL} \mathrm{~h}^{-1}$. The polymer properties (i.e., concentration, resistivity) and other parameters of the process (i.e., flow rate, an applied voltage) strongly influenced the size of the fibers. Plasma treatment of nanofibers resulted in reduced biofilm formation on their surface. The results of photo-bactericidal activity (i.e., up to $180 \mathrm{~min}$ ) confirmed the high efficiency of inactivation of Staphylococcus aureus cells using fibers containing methylene blue (i.e., with and without plasma treatment). The most effective reduction in the number of biofilm cells was equal to $99.99 \pm 0.3 \%$.
\end{abstract}

Keywords: cellulose acetate nanofiber; electrospinning; methylene blue; non-thermal plasma

\section{Introduction}

In the current situation of a global epidemiological threat, the use of materials with limited ability to develop surface biofilm, especially in public facilities, is of great importance. On the other hand, the growing resistance of pathogens to commercially available biocides necessitates the search for antimicrobial materials that act on many cellular targets and limit the development of pathogen resistance. Antimicrobial photodynamic therapy (APDT) seems to be a unique and interesting technique for controlling pathogens. This process is based on the release of ROS from the non-toxic photosensitizer in the presence of $\mathrm{O}_{2}$ after irradiation with light of an appropriate length. Cytotoxic ROS, similarly to hydroxyl radicals and singlet oxygen, are produced in cells and cause harmful biological effects (i.e., lipid peroxidation, enzymatic inhibition, protein agglutination) [1].

To develop platform technologies for anti-infective materials based upon photodynamic inactivation, we employed electrospinning to prepare polymeric nanofibers comprised of cellulose acetate (CA) embedded with methylene blue as a photo-active compound.

The electrospinning process is performed by injecting a liquid polymer solution with a syringe in the presence of a strong electric field. The liquid polymer is extracted from the capillary (i.e., usually a small diameter needle) connected to DC high voltage power supply, and then the nanofibers after evaporation of the solvent (or solvent mixture) are deposited on the grounded collector. The electrospinning process takes place in the atmospheric air of fixed relative humidity. Electrospinning is characterized by the possibility of scaling, the 
convenience of use, repeatability, and the ability to control the fiber size. This process is also is economically efficient, which is crucial for industrial purposes. On the other hand, in this process, there may be a problem of instability of the jet from which the nanofiber is obtained. Important factors influencing electrospinning are [2-4]:

- The appropriate dissolution of the polymer;

- The viscosity and surface tension of the solvent;

- Supply voltage (or electric field);

- The distance between the capillary (at high potential) and a grounded surface (collector).

The technology described above is successfully applied to fabricate micro- and nanofibers from various natural and synthetic polymers [2-4]. The small variety of pores, the large surface area, and the high porosity of electrospun mats make them ideal materials to protect against pathogenic microorganisms. An excellent fit of electrospun mats means that they can provide highly effective delivery platforms for bioactive ingredients such as antimicrobials, and these chemicals are typically incorporated into electrospun materials by mixing with an encapsulating polymer solution or by coaxial electrospinning to form a core-shell structure [5].

Several electrospun materials based on the photodynamic mode of operation have recently been described. For example, de Faria et al. [6] demonstrated antibacterial mats made of a mixture of poly (lactide-co-glycolide) (PLGA) and chitosan. These PLGA-chitosan mats have been functionalized with graphene oxide decorated with silver nanoparticles (GO-Ag) as a result of a chemical reaction between graphene carboxyl groups and primary amine functional groups on PLGA-chitosan fibers.

Stanley et al. [7] used electrospinning to prepare a non-woven fabric composed of polyacrylonitrile nanofibers embedded in a cationic photosensitizer based on porphyrin; referred to as PAN-Por (+). Antimicrobial activity was assessed against bacteria belonging to the ESKAPE family of pathogens (Staphylococcus aureus, vancomycin-resistant Enterococcus faecium, Acinetobacter baumannii, and Klebsiella pneumoniae) as well as Escherichia coli. It was shown that these nanofibers showed an extensive photodynamic inactivation of all tested bacterial strains after irradiation ( $30 \mathrm{~min}, 65 \pm 5 \mathrm{~mW} \mathrm{~cm}^{-2}, 400-700 \mathrm{~nm}$ ) with a minimum of $99.9996+\%$ (5.8 log units) regardless of taxonomic classification.

The BODIPY cationic photosensitizer, embedded by electrospinning in nylon and polyacrylonitrile (PAN) nanofibers, capable of inactivating bacteria and viruses by antibacterial photodynamic inactivation was described by Stoll et al. [8]. The antimicrobial properties of these materials were studied against bacteria recognized by the World Health Organization as critical or high priority pathogens: methicillin-resistant S. aureus (MRSA), vancomycin-resistant E. faecium (VRE), multi-drug resistant A. baumannii (MDRAB), and K. pneumoniae (KP). The obtained results showed the detection limit $(99.9999 \%)$ of the three strains after irradiation (30-60 $\mathrm{min}, 40-65 \pm 5 \mathrm{~mW} \mathrm{~cm}^{-2}, 400-700 \mathrm{~nm}$ ): MRSA, VRE, and MDRAB.

Due to the ubiquitous nature and long-term contact with humans, cellulose and its derivatives are generally considered the safest and most acceptable group of polymers for use in pharmaceutical products, therefore, as mentioned above, cellulose acetate has been applied in our experiments.

Cellulose acetate (CA) is a polymeric material exhibiting biodegradability, biocompatibility, good thermal stability, and chemical resistance. Moreover, other properties of this polymer are aesthetics, smoothness, a delicacy of the product surface, and the low price of the polymer. Cellulose acetate is commonly used for the fabrication of fibers, membranes, or films $[9,10]$. Many recent studies have been focused on the possibility of using electrospun cellulose acetate nanofibers as a drug carrier. Some studies relate to the production of fibrous CA mats used as wound dressing, e.g., electrospun CA/silversulfadiazine nanofibers [11]. These nanofibers exhibited significant antimicrobial activity against selected bacteria. Furthermore, electrospun CA/gelatin/hydroxyapatite mat acting as a fibrous dressing was effectively applied in the wound healing process [12]. 
Methylene blue (MB) may be used as a photosensitizer because it is a well-known synthetic non-porphyrin compound compatible with the wavelength of visible light (up to $685 \mathrm{~nm}$ ) and is characterized by high ROS production efficiency [13]. MB has been used as an antimicrobial compound and has been used in conventional (non-light) antimicrobial therapy for over 100 years [14]. Some studies have described its activity in vitro and in animal models of infection, and MB has obtained regulatory approval for the mediation of photodynamic therapy (PDT) in infectious dental diseases, such as periodontitis and caries [13-15]. In recent years, the toxicity of this dye has been shown more often, but these observations concern internal use. It has been observed that methylene blue caused central nervous system (CNS) toxicity, variously described as encephalopathy, central nervous system toxicity, serotonin syndrome (SS), or serotonin toxicity (ST) [16]. Nevertheless, this dye is on the list of essential medicines of the World Health Organization [17]. In addition, the wide application possibilities of this compound, its toxicity, safety, and hazards have been described by the National Institutes of Health (NIH) that is an open chemistry database [18].

The development of new technologies in polymer materials is closely related to the progress in fiber surface chemistry and functionalization. Among many methods of polymer surface modification, non-thermal plasma treatment is a well-known and highly effective technique that allows achieving the required surface properties. Non-thermal plasma as an ionized gas (i.e., containing excited particles, high-energy electrons, free radicals, photons, and neutral atoms) has been successfully used for surface treatment of polymeric materials, including nanofibers in processes such as cleaning, functionalization, grafting, and interstitial modification [19-23]. Plasma technologies do not involve the use of chemical reagents, which are particularly undesirable in the alteration of materials that may have biomedical applications [24-26]. Plasma treatment of nanofibers can be applied to improve biocompatibility (e.g., cell-material interaction), regenerate bone or different types of tissues, immobilize proteins or enzymes onto nanofiber surface, promote bioactivity and change mechanical parameters of nanofibers [27-31]. Another important advantage of plasma treatment is the ability to change the surface properties of the polymer, namely the chemical structure, morphology, hydrophilicity, and surface charge, by changing some plasma treatment parameters [32].

In this study, for the first time (according to our extensive knowledge), electrospun nanofibers of cellulose acetate and photoactive methylene blue as photosensitizer were fabricated and the surface of the prepared material was modified with the non-thermal atmospheric plasma. The properties of the obtained nanofibers were investigated and the antibacterial effect against Staphylococcus aureus of this photo-active material in pristine and plasma-treated samples (i.e., before and after plasma treatment) was examined.

\section{Materials and Methods}

\subsection{Cellulose Acetate (CA) Nanofibers}

In our research, two different types of polymeric nanofibers were tested: pure CA nanofibers and CA nanofibers with the addition of methylene blue (MB). Cellulose acetate $\left(\mathrm{CA}, M_{w}=30 \mathrm{kDa}\right)$ was purchased from Sigma-Aldrich (Poland). Acetone and methylene blue were purchased from $\mathrm{POCH}$ (Poland). All the reagents were used as received without further purification.

For the electrospinning process, the CA was dissolved in a mixture of acetone and distilled water $\left(9: 1, \mathrm{vv}^{-1}\right)$ at room temperature and stirred for $12 \mathrm{~h}$ to ensure complete dissolution. The concentration of CA was in the range of $10-21 \%\left(\mathrm{wv}^{-1}\right)$. Methylene blue solution (MB) was prepared by dissolving the powdered dye in distilled water and sterilized it by filtration through $0.22-\mu \mathrm{m}$ pore diameter membranes (Millex ${ }^{\circledR}$-HP syringedriven filter unit, Darmstadt, Germany). After filtration, the photosensitizer solution was stored in the dark. To prepare the working fluid, $10 \mathrm{mg}$ of MB was placed into a $10 \mathrm{~mL}$ solvent mixture of acetone and distilled water $\left(9: 1 \mathrm{vv}^{-1}\right)$. Then, $1.7 \mathrm{~g}$ of cellulose acetate 
powder was added to the dye solution and this mixture was stirred using a magnetic stirrer for $12 \mathrm{~h}$.

\subsection{Fabrication of Nanofibers}

The electrospinning process was carried out in the system presented in Figure 1. A $2 \mathrm{~mL}$ syringe with the dissolved CA was placed in an injection pump (NE-300, New Era Pump Systems Inc., Farmingdale, NY, USA) connected to DC high voltage source (SP/EW50P12.0Y17, Glassman High Voltage Inc., Califon, NJ, USA). The distance from the needle tip to the collector was $80 \mathrm{~mm}$ and the nanofibers were collected on the metallic plate covered with aluminum foil (an area equal to $400 \mathrm{~cm}^{2}$ ) forming a thin film. During electrospinning, the inner diameter of the needle, electrospinning voltage, injection rate, environmental temperature, and humidity were $0.5 \mathrm{~mm}, 10-14 \mathrm{kV}, 0.1-2.0 \mathrm{~mL} \mathrm{~h}^{-1}, 298 \pm 2 \mathrm{~K}$, and $34 \pm 2 \%$, respectively.

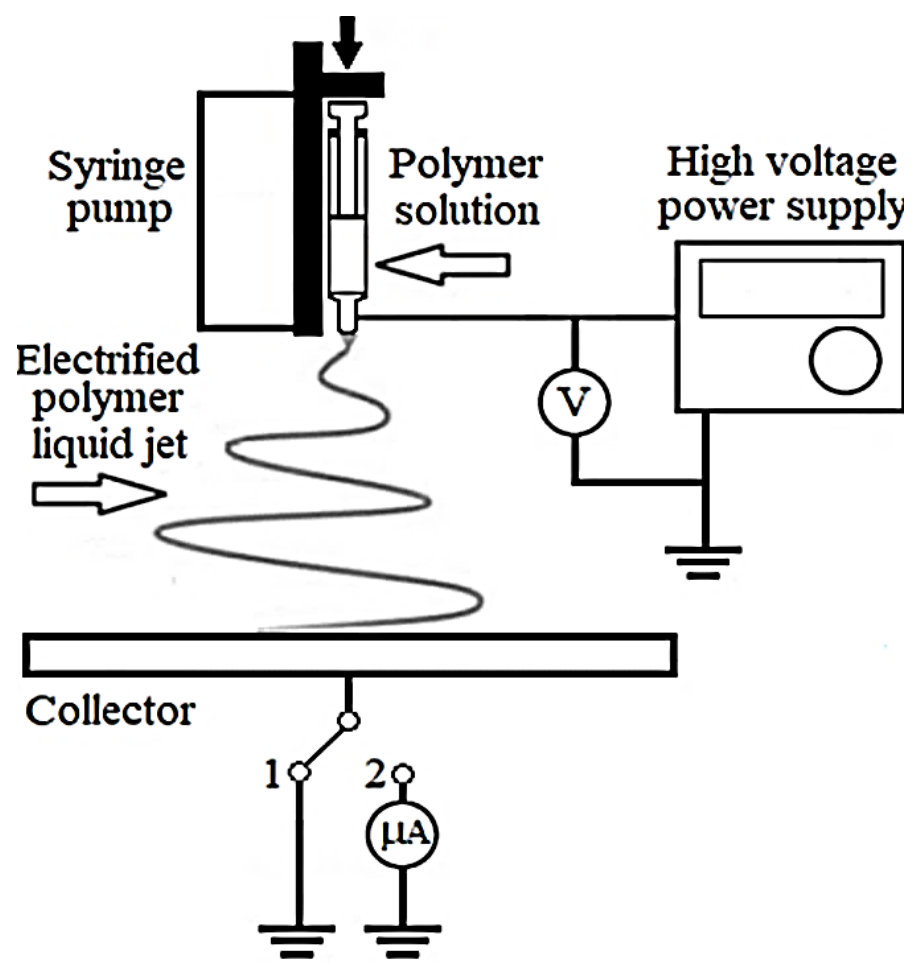

Figure 1. Scheme of the system for the fabrication of electrospun nanofibers.

\subsection{Current-Voltage Characteristics of the Process}

The current-voltage characteristics of the electrospinning process were measured in the experimental system presented in Figure 1 with the collector grounded by a current meter (AP100, WUST, Wroclaw, Poland). In addition, power supply conditions were adjusted to ensure the stability of the electrospinning process and fibers with the required morphology.

\subsection{Plasma Treatment of Nanofibers}

Plasma treatment of pure polymer nanofibers and those containing methylene blue was conducted using a dielectric barrier discharge (DBD) plasma reactor operating in the air at atmospheric pressure. The plane-parallel plasma reactor was powered by a high voltage pulse generator with a modulated frequency (Dora PS, Wroclaw, Poland). The pulses amplitude, frequency, and discharge power were $5.0 \mathrm{kV}, 38 \mathrm{kHz}$, and $2 \mathrm{~W}$, respectively. Before plasma treatment, the fibers were deposited on a glass substrate (i.e., an area of $25 \times 25 \mathrm{~mm}$ and thickness of $1 \mathrm{~mm}$ ), and then the samples were placed in the reactor and exposed to non-thermal plasma for $15 \mathrm{~s}$. The average value of power density, dissipated on the fiber-mats was $17 \mathrm{~mW} \mathrm{~cm}^{-2}$. 


\subsection{Characterization of Electrospun Nanofibers}

\subsubsection{Resistance Measurements}

The resistivity of polymer solution (i.e., cellulose acetate and solvent), from which the nanofibers were obtained, as well as the resistivities of pure CA and CA/MB, were determined. The resistance measurements were carried out using a resistance meter (152-1, TREK INC., Lockport, NY, USA). The volume resistivity of tested material (after solvent evaporation was estimated from the resistance measurements:

$$
\rho=R \cdot \frac{S}{h^{\prime}}
$$

where: $\rho$-resistivity, $R$-resistance of the sample, $S$-area of the measuring electrode, $h$-the distance between electrodes or foil thickness.

In the case of liquids, the sample resistance was measured using a plane-parallel electrode system containing two electrodes (area $S=1 \pm 0.04 \mathrm{~cm}^{2}$ ) kept at a distance $h=1.0 \pm 0.05 \mathrm{~mm}$ and immersed in the investigated liquid. For solid polymers, the samples in a form of foil were clamped between elastic electrodes (additional equipment of the resistance meter).

\subsubsection{UV-Vis Analysis}

The spectroscopic measurements of $\mathrm{MB}, \mathrm{CA}$, and CA/MB in the range of 450-800 nm were carried out using a spectrophotometer (Shimadzu, UV 3600, Tokyo, Japan).

\subsubsection{FT-IR Analysis}

The chemical structure of the obtained $\mathrm{CA}$ and $\mathrm{CA} / \mathrm{MB}$ nanofibers was assayed with a Fourier transform infrared (FTIR) spectrometer (VERTEX 80v; Bruker Optics, Bremen, Germany).

\subsubsection{Microscopic Examination of Nanofibers}

The morphology and diameter of the fabricated CA and CA/MB nanofibers were examined on a scanning electron microscope (SEM, JSM-6610LV, JEOL Ltd., Akishima, Japan). The fiber diameter was measured using ImageJ software. The average diameter of each sample was calculated from at least 20 measurements.

\subsubsection{Contact Angle and Surface Free Energy Measurements}

The wettability of the electrospun fibers was determined by contact angle and surface free energy measurements. The tests were carried out using a portable See System E device (Advex Instruments, s. r. o., Brno, Czech Republic). Initially, the fibers were deposited on a glass substrate forming a mat. Next, glycerine drops with a volume of $6 \mu \mathrm{L}$ were used for testing. Tests were performed in air at a temperature of $295 \pm 2 \mathrm{~K}$, the pressure of $1000 \pm 5 \mathrm{hPa}$, and relative humidity of $40 \pm 3 \%$. The test results were given as the arithmetic mean of three individual experiments.

\subsection{Studies on Formation and Photodynamic Inactivation of Biofilm Formed by Staphylococcus aureus \\ 2.6.1. Culture Conditions}

An amount of $5 \mathrm{~mL}$ of an overnight culture of S. aureus ATCC 25923 (grown aerobically at $310 \mathrm{~K}$, with shaking, in Mueller broth) was centrifuged at $5000 \mathrm{~g}$ for $10 \mathrm{~min}$ and the supernatant was discarded. The pellet was resuspended in $5 \mathrm{~mL}$ phosphate buffered saline (PBS) to give an inoculum of approximately $1.2 \times 10^{6}$ colony-forming units $\left(\mathrm{CFU} \mathrm{mL}{ }^{-1}\right)$.

\subsubsection{Photodynamic Inactivation of Biofilm Formed by S. aureus}

The CA/MB nanofibers obtained by the electrospinning technique (i.e., before and after treatment with non-thermal plasma for $15 \mathrm{~s}$ ) were transferred to the wells of a microtiter plate (F.L. Medical S.r.l., Torreglia, Italy). Each well contained approximately 
$3 \mathrm{mg}$ of MB/CA nanofibers. Then, $150 \mu \mathrm{L}$ of a standardized S. aureus suspension (see Culture conditions) was added and all samples were incubated for $5 \mathrm{~h}$ at $310 \mathrm{~K}$ in a shaker (50 rpm) to ensure adhesion of bacterial cells to the surface of the fibers. Each fiber sample was then gently washed using $150 \mu \mathrm{L}$ phosphate buffered saline (PBS) and transferred to $150 \mu \mathrm{L}$ of the fresh medium. The plate was further incubated for $24 \mathrm{~h}(310 \mathrm{~K})$. After $24 \mathrm{~h}$ biofilm formation, the $\mathrm{CA} / \mathrm{MB}$ nanofibers were again washed twice with $150 \mu \mathrm{L}$ of PBS and three samples of each fiber type were exposed to the neon tube (GLO Aqua-Glo, Hagen, Germany) with a wavelength in the range from 400 to $700 \mathrm{~nm}$ for $30 \mathrm{~min}, 90 \mathrm{~min}$, and $180 \mathrm{~min}$. The employed lamp provided two peak-power wavelengths equal to 430 and $660 \mathrm{~nm}$ with an output power of $30 \mathrm{~W}$. Three samples of each type of fiber were stored in the dark to determine the initial cell concentration in the biofilms (i.e., the efficiency of biofilm formation was estimated). Then, the fiber samples (control and light irradiated) were separately transferred to Falcon tubes containing $5 \mathrm{~mL}$ of PBS. To disrupt the biofilms, the contents of the tubes were homogenized for 10,20, or $30 \mathrm{~s}$ using an ultrasonic homogenizer (VC505, Sonics and Materials Inc., Newtown, CT, USA) with an output power of $50 \mathrm{~W}$. The effectiveness of disrupting the biofilm after different times of ultrasound treatment was examined by the serial dilution method. For this, a series of tenfold dilution of PBS (after the homogenization) were made sequentially and $100 \mu \mathrm{L}$ aliquots of each dilution were seeded in duplicate onto Mueller agar (Difco) and incubated for 24-48 h at $310 \mathrm{~K}$. After incubation, the number of colonies forming units was counted, and the number of viable cells was given as CFUmg ${ }^{-1}$ and $\log _{10}(N)$ cells $\mathrm{mg}^{-1}$. The obtained results showed that the most viable cells were observed in PBS after $10 \mathrm{~s}$ of ultrasound treatment. When the biofilm was sonicated for 20 and $30 \mathrm{~s}$, the number of viable cells in the suspension was reduced by approximately 20 and 35\%, respectively (if compared to $10 \mathrm{~s}$ ultrasound treatment). Ten-second homogenization of the fibers with the biofilm on the surface was used in all experiments.

To evaluate the bactericidal effect of light irradiation, the percentage reduction (\%) of S. aureus was calculated using the following formula. The reduction in viability is given:

$$
R=\frac{N_{0}-N}{N_{0}} \cdot 100
$$

where $N_{0}$ is the number of CFUs at initial $\left(1.585 \times 10^{8}\right.$ and $1.25 \times 10^{6}$ colony-forming units $\left(\mathrm{CFUmg}^{-1}\right)$ for the $\mathrm{MB} / \mathrm{CA}$ fibers untreated and treated with the non-thermal plasma, respectively; $N$ is the number of CFUs remaining in suspensions after light irradiation.

The effect of non-thermal plasma treatment on the efficiency of biofilm formation on the surface of CA/MB nanofibers was also studied using the SEM technique (Quanta 250, FEI, Hillsboro, OR, USA). The samples of the nanofibers were fixed in $2.5 \%$ glutaraldehyde for $24 \mathrm{~h}$ at $277 \mathrm{~K}$. Then, the samples were washed three times with $0.1 \mathrm{M}$ sodium phosphate at $\mathrm{pH}$ 7. Next, the material was then dehydrated in graded ethanol series (from $50 \%$ to $100 \%)$. After dehydratation, the excess liquid was removed, the samples were air-dried and coated with gold.

\subsection{Statistical Analysis}

Statistical analyses were carried out using STATISTICA (ver. 10.0) and Excel. The quantitative data were presented by the arithmetic mean of standard deviation or median or $\max / \mathrm{min}$ (range) and 95\% confidence interval. Statistical significance of differences between two samples was determined with the Student's $t$ test. A $p$ value of 0.05 was established as the cut-off value in all calculations.

\section{Results}

\subsection{Physical and Electrical Properties of $C A$ and $C A / M B$ Nanofibers}

In the first part of the study, the morphology of nanofibers obtained for different input parameters of the process (e.g., flow rate, applied voltage, and polymer concentration) was checked. The sample SEM images were shown in Figure 2. It can be seen that the 
CA nanofibers had a regular shape and smooth surface, and no defects (e.g., beads) were observed. It was noticed that cylindrical fibers were fabricated for all tested polymer concentrations. On the other hand, $\mathrm{CA} / \mathrm{MB}$ nanofibers were characterized by greater differences in the diameter of individual fibers and some of them had a ribbon shape (see Figure $2 b$ ). In addition, no formation of crystals or other aggregates of methylene blue was noticed on the fiber surface. This outcome indicates that the methylene blue was uniformly distributed in the polymer solution.

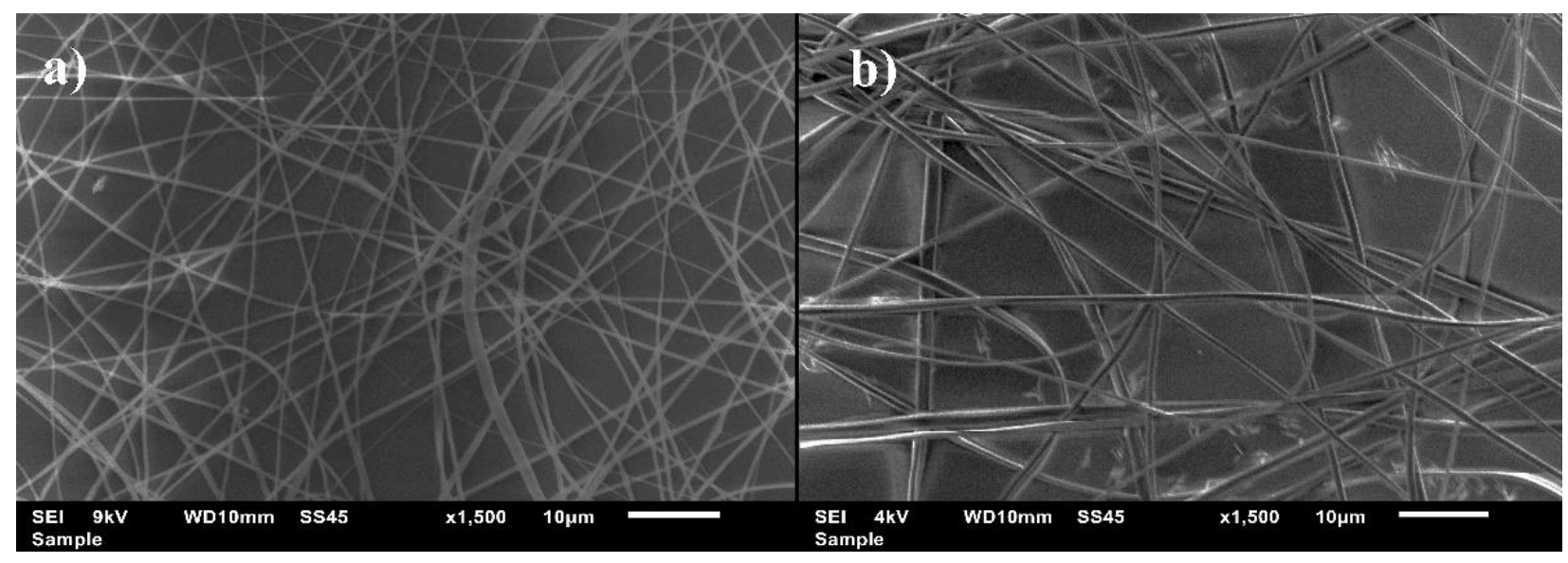

Figure 2. SEM micrograph (a) of CA nanofibers (b) and CA/MB. Results were obtained for the supply voltage, polymer concentration, and flow rate equal to $10 \mathrm{kV}, 17 \%$, and $1 \mathrm{~mL} \mathrm{~h}^{-1}$, respectively.

Many researchers report that it is essential to adjust the conditions of the electrospinning process to receive uniform nanofibers in a recurrent form [33-35]. The most common known faults that occur in the electrospinning process are: (a) beaded, (b) branched, (c) buckled, and (d) flat nanofibers [36]. In our research, we do not consider the obtained flat nanofibers containing methylene blue to be defective because they were continuous and reproducible during their fabrication. In a later part of the work, we checked their utility for biological purposes which were not affected by their shape.

The results of the calculated resistivity of liquid polymer containing solvent (CA concentration equal to $17 \%$ ), pure cellulose acetate, and cellulose acetate with methylene blue after evaporation of the solvent were shown in Table 1.

Table 1. The resistivity of the polymer solutions, pure cellulose acetate, and cellulose acetate with methylene blue.

\begin{tabular}{cc}
\hline Material & Resistivity $\rho[\Omega \mathrm{m}]$ \\
\hline $\begin{array}{c}\text { Liquid polymer } \\
\text { (CA with solvent) } \\
\text { Pure polymer } \\
\text { (CA, and no solvent) } \\
\text { Liquid polymer + methylene blue } \\
\quad(\mathrm{CA} / \mathrm{MB} \text { with solvent) } \\
\begin{array}{c}\text { Polymer + methylene blue } \\
\text { (CA/MB, and no solvent) }\end{array}\end{array}$ & $3.1 \times 10^{3}$ \\
\hline
\end{tabular}

Resistivity measurements confirmed that both polymer-solvent mixtures used are conductive ( $\rho$ at the level of $10^{3} \Omega \mathrm{m}$ ), while the resistivity of solid polymers (i.e., after solvent evaporation) is $7-8$ orders of magnitude higher and corresponds to the resistivity of dielectrics.

Moreover, it was found that pure cellulose acetate has a higher resistivity compared to the solution with methylene blue (i.e., the difference of one order of magnitude). 


\subsection{Influence of Polymer Concentration and the Process Parameters on the Fiber Diameter}

In the next step, the influence of the polymer concentration on CA fiber diameter was examined and the results of the measurements were presented in Figure 3. For this purpose, nanofibers were prepared using eight different polymer concentrations (i.e., from 10 to $21 \% \mathrm{wv}^{-1}$ ). Electrospinning was carried out using a flow rate of $0.5 \mathrm{~mL} \mathrm{~h}^{-1}$ and an applied voltage of $12 \mathrm{kV}$. The results confirmed that nanofiber diameters increase as the polymer concentration increases, i.e., from $490 \mathrm{~nm}$ (for $c_{p}=10 \%$ ) to $690 \mathrm{~nm}$ (for $c_{p}=21 \%$ ). Since the increase in fiber diameter seems to develop with increasing polymer concentration (especially in the region above $17 \%$ ), the middle polymer concentration (i.e., $17 \%$ ) was chosen as representative, i.e., MB was added to this solution later in the study.

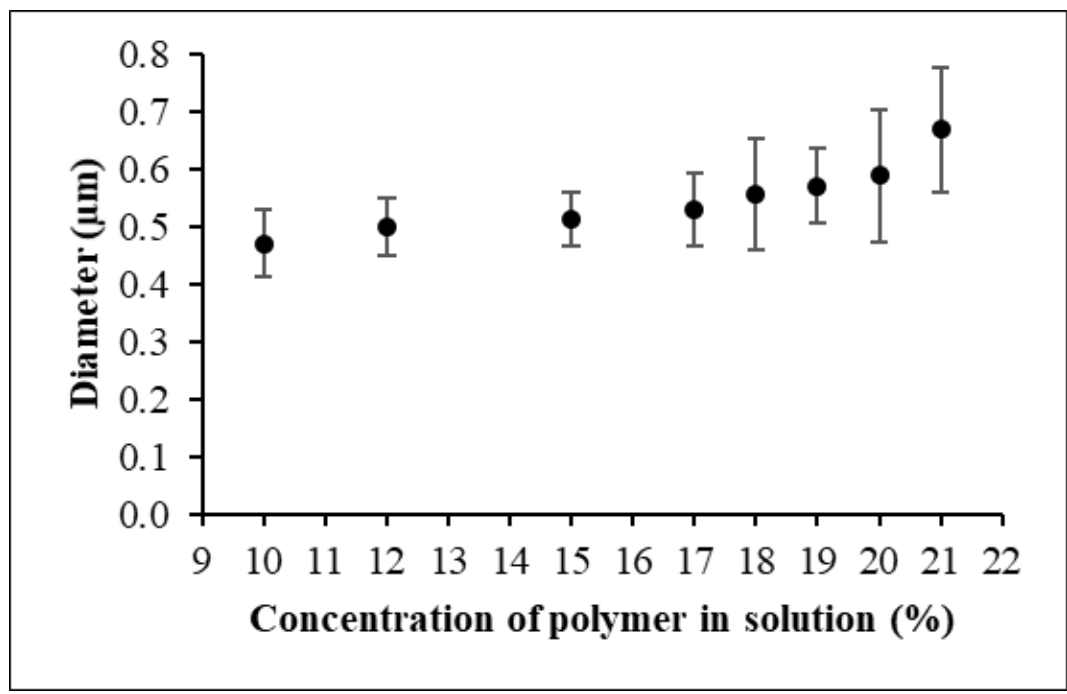

Figure 3. The influence of concentration of polymer on CA fiber diameter. Results were obtained for the supply voltage, and flow rate equal to $12 \mathrm{kV}$, and $0.5 \mathrm{~mL} \mathrm{~h}^{-1}$, respectively.

The impact of other process conditions on fiber diameters was checked for CA solution with a concentration of $17 \%$.

Results of flow rate in the range $0.1-1.5 \mathrm{~mL} \mathrm{~h}^{-1}$ for a fixed voltage of $12 \mathrm{kV}$ on the nanofiber diameter were shown in Figure 4.

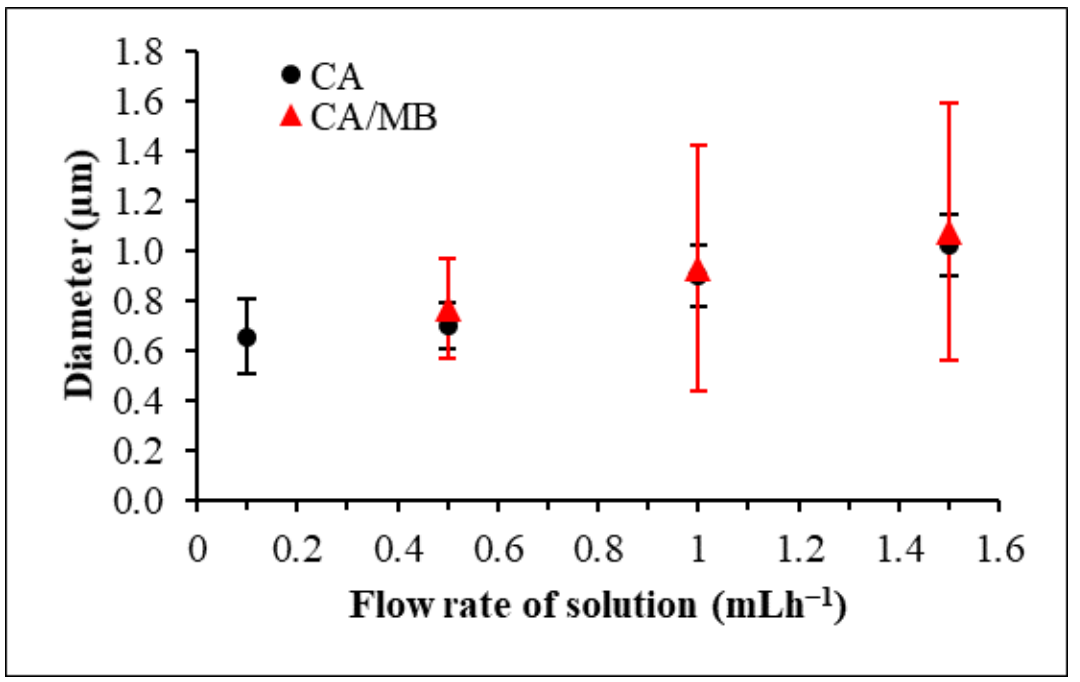

Figure 4. The influence of flow rate on $\mathrm{CA}$ and $\mathrm{CA} / \mathrm{MB}$ fiber diameter. Results were obtained for the supply voltage, and polymer concentration equal to $12 \mathrm{kV}$ and $17 \%$, respectively. 
As can be seen, the average value of fiber diameter increases as the flow rate of the polymer solution increases. Our results are consistent with the studies carried out by other researchers [34,37]. For the highest flow rate equal to $1.5 \mathrm{~mL} \mathrm{~h}^{-1}$, the fabricated fibers had diameters above $1000 \mathrm{~nm}$ and were 50\% larger than those obtained for the flow rate of $0.1 \mathrm{~mL} \mathrm{~h}^{-1}$. Moreover, the diameters of CA/MB fibers showed less homogeneity and the calculated standard deviation was greater than that of pure CA fibers. This outcome was related to the presence of ribbon-shaped nanofibers. It was also found that for the flow rate lower than $0.5 \mathrm{~mL} \mathrm{~h}^{-1}$, the electrospinning process for CA/MB fiber production was disrupted due to the nozzle (needle) sticking.

The influence of supply voltage on fiber diameters for a fixed flow rate is shown in Figure 5. The obtained results indicate that the diameter of nanofibers decreases with increasing supply voltage. Fibers of $1000 \mathrm{~nm}$ and $500 \mathrm{~nm}$ diameter were obtained for $10 \mathrm{kV}$ and $14 \mathrm{kV}$, respectively. In the case of $\mathrm{CA} / \mathrm{MB}$ solution, no fibers were produced for the voltages higher than $12 \mathrm{kV}$, i.e., the mixture aerosol was observed instead.

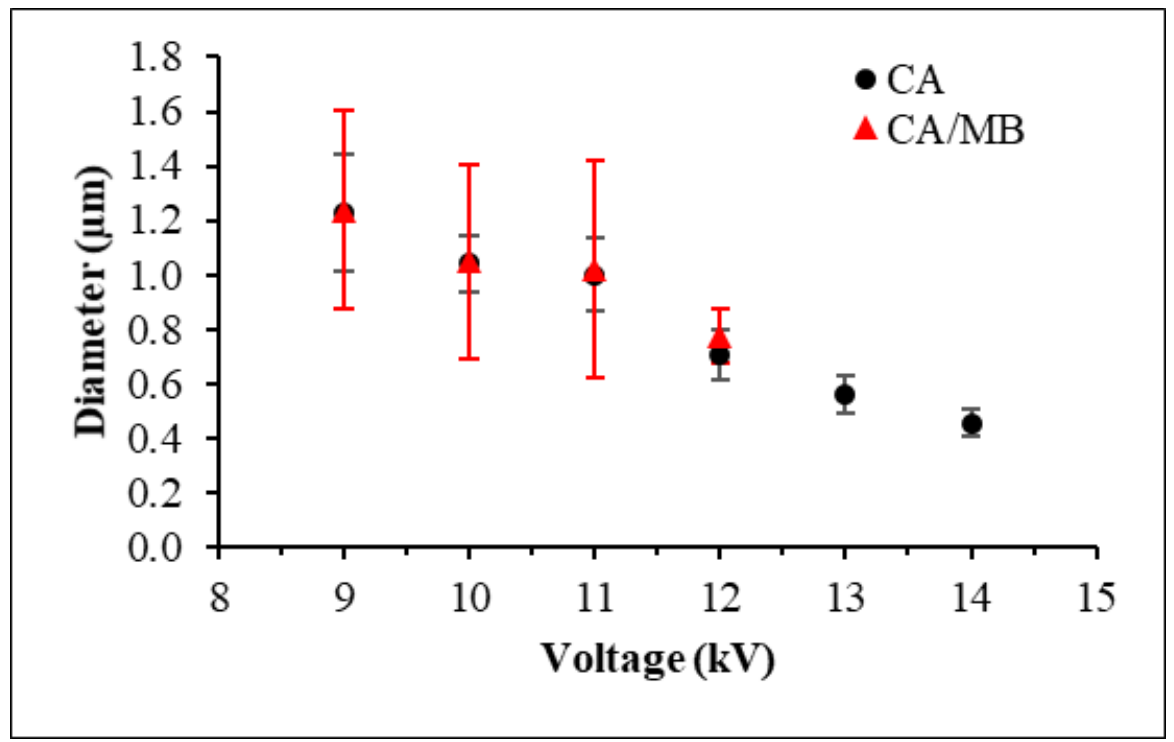

Figure 5. The influence of voltage applied to the nozzle on CA and CA/MB fiber diameter. Results were obtained for the polymer concentration, and flow rate equal to $17 \%$ and $0.5 \mathrm{~mL} \mathrm{~h}^{-1}$, respectively.

\subsection{Electrical Properties of the Electrospinning Process}

Electrical properties of the electrospinning process can be determined by the characteristic voltages $V_{\text {start }}$ and $V_{\text {stop }}$, which correspond to the start and stop voltages of the process, respectively. $V_{\text {start }}$ refers to the voltage for which the surface tension is overcome and nanofibers are formed from the Taylor cone. On the contrary, $V_{\text {stop }}$ means the voltage for which there is no fiber but aerosol particles occur.

The results of $V_{\text {start }}$ and $V_{\text {stop }}$ measurements obtained for flow rate equal to $0.5 \mathrm{~mL} \mathrm{~h}^{-1}$ were presented in Figure 6. For CA/MB solution both voltages, $V_{\text {start }}$ and $V_{\text {stop, }}$, are lower than for the pure CA solution (i.e., data given for a polymer concentration of $17 \%$ ). $V_{\text {start }}$ dependency determines the minimum nozzle supply voltage for fiber spinning from the solution with the required polymer concentration.Results shown in Figure 6 confirmed, that the electrospinning process for solutions with polymer concentration varying in the range from 10 to $21 \% \mathrm{wv}^{-1}$ is continuous and stable for a minimum supply voltage higher than $8 \mathrm{kV}$. Finally, using dependencies shown in Figures 5 and 6 the nozzle supply voltage of $12 \pm 0.1 \mathrm{kV}$ was chosen. 


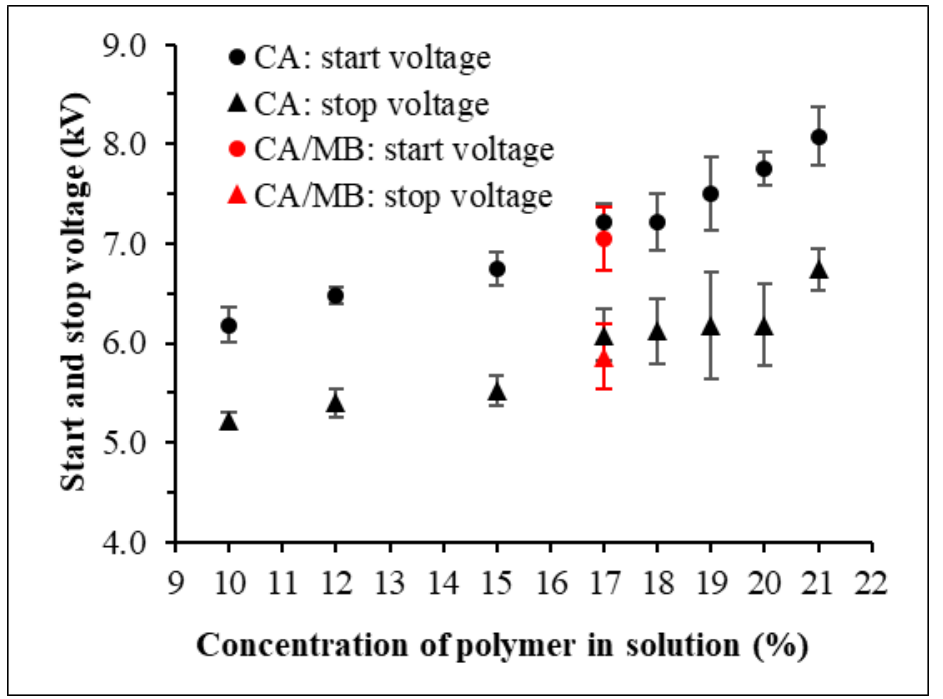

Figure 6. $V_{\text {start }}$ and $V_{\text {stop }}$ characteristics for CA and CA/MB fibers. Results were obtained for the flow rate equal to $0.5 \mathrm{~mL} \mathrm{~h}^{-1}$.

Current-voltage $(I-V)$ characteristics for the electrospinning system (i.e., containing nozzle, liquid/solid fiber, and collector-see Figure 1) can be useful for the investigation and characterization of the electrospinning process. Results shown in Figure 7 were obtained for different polymer solutions (i.e., pure CA and CA-MB doped) and for two flow rates (i.e., $0.5 \mathrm{~mL} \mathrm{~h}^{-1}$ and $1 \mathrm{~mL} \mathrm{~h}^{-1}$ ).

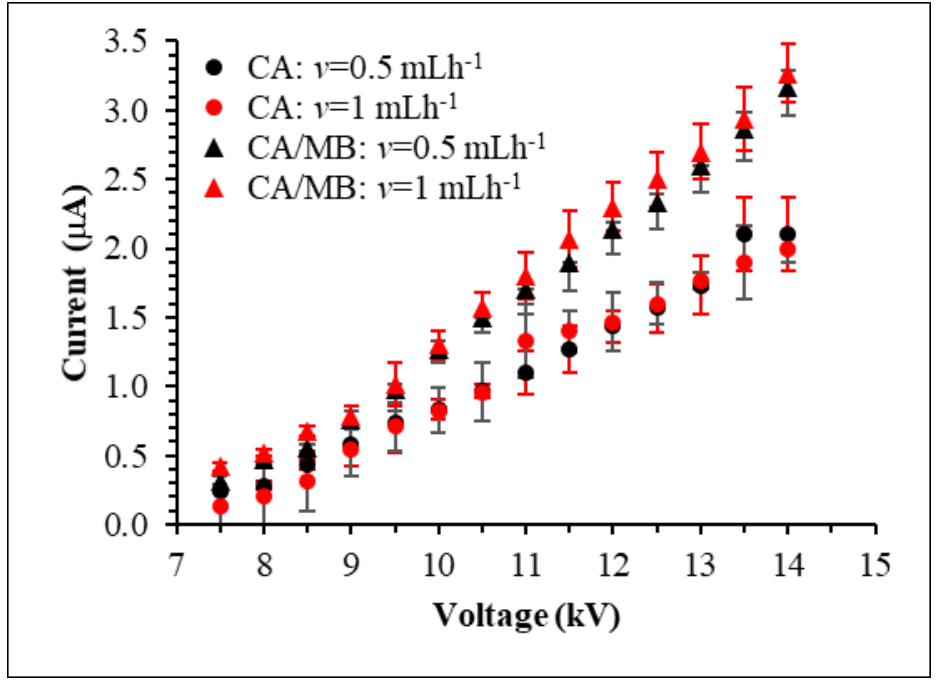

Figure 7. Current-voltage characteristics of the electrospinning process for CA and CA/MB fibers. Results were obtained for the polymer concentration equal to $17 \%$.

It can be noted that for $\mathrm{CA} / \mathrm{MB}$ solution, higher current values were obtained for the same power supply conditions. This effect can be directly associated with the different conductivity of the tested solutions (assuming that the electrospun fiber is not completely dried when placed between the nozzle and collector). This outcome can be partially confirmed by nearly linear $I-V$ dependency for voltages $V>V_{\text {start }}$ observed for both characteristics. It should be noted that the conduction current calculated for the particular voltage (and the proper fiber diameter) and resistivity of the solution, is comparable to the measured current values. Some nonlinearities seen in $I-V$ characteristics may be due to the corona discharges from the fiber (its conducting part) or the nozzle. The detailed explanation of the observed $I-V$ characteristics requires additional investigations. 


\subsection{The Effect of Plasma Treatment on Fiber Wettability}

In the next step of our experiments, the obtained electrospun $\mathrm{CA}$ and $\mathrm{CA} / \mathrm{MB}$ nanofibers (i.e., untreated and treated with the non-thermal plasma for $15 \mathrm{~s}$ ) in terms of their wettability. The results of measurements of contact angle and surface free energy for the tested fibers were given in Tables 2 and 3. Example images of glycerine drops placed on a nanofiber layer (i.e., in the form of a mat) are shown in Figure 8.

Table 2. Contact angles for untreated and treated with plasma electrospun nanofibers.

\begin{tabular}{ccccc}
\hline \multirow{2}{*}{ Concentration of $\mathbf{M B}\left(\mathbf{m g ~ m L}^{-\mathbf{1}}\right)$} & \multicolumn{4}{c}{ Contact Angle $\left.\mathbf{(}^{\circ}\right)$} \\
\cline { 2 - 5 } & $\mathbf{0 ~ s}$ & $\mathbf{1 5 ~ s}$ & $\mathbf{3 0 ~ s}$ & $\mathbf{6 0 ~ s}$ \\
\hline 0 & 115 & 115 & 115 & 109 \\
2.5 & 68 & 21 & 20 & 27 \\
5 & 66 & 50 & 26 & 30 \\
10 & 52 & 47 & 135 & 132 \\
\hline
\end{tabular}

Table 3. Surface free energies for untreated and treated with plasma electrospun nanofibers.

\begin{tabular}{ccccc}
\hline \multirow{2}{*}{ Concentration of $\mathbf{M B}\left(\mathbf{m g ~ m L}^{-\mathbf{1}}\right)$} & \multicolumn{4}{c}{$S F E\left(\mathbf{m J ~ m}^{-\mathbf{2}}\right)$} \\
\cline { 2 - 5 } & $\mathbf{0 ~ s}$ & $\mathbf{1 5} \mathbf{~ s}$ & $\mathbf{3 0 ~ s}$ & $\mathbf{6 0 ~ s}$ \\
\hline 0 & 5 & 5 & 5 & 7 \\
2.5 & 30 & 60 & 60 & 57 \\
5 & 32 & 43 & 58 & 56 \\
10 & 42 & 45 & 1 & 2 \\
\hline
\end{tabular}

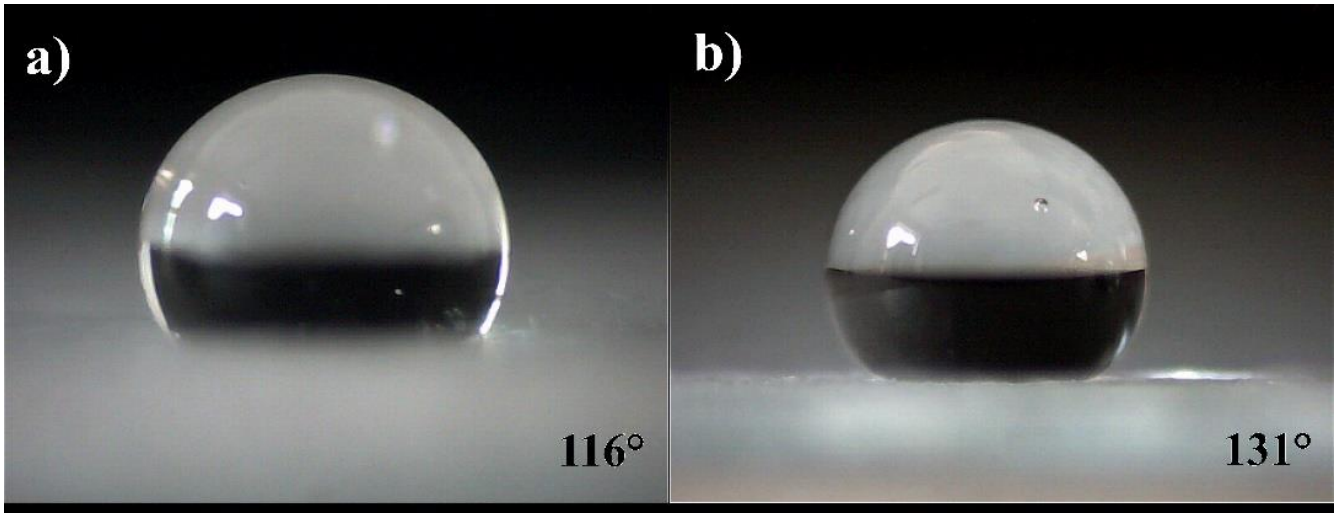

Figure 8. Images of glycerine drop on pure cellulose acetate nanofibers without plasma treatment (a) and cellulose acetate + methylene blue $\left(10 \mathrm{mg} \mathrm{mL}^{-1}\right)$ nanofibers after 60 -s non-thermal plasma treatment (b). Results were obtained for the polymer concentration equal to $17 \%$.

The surface of pure CA nanofibers exhibits hydrophobic properties (contact angle of $115^{\circ}$ ). The $\mathrm{CA} / \mathrm{MB}$ nanofibers feature enhanced wettability. From the obtained results, it can be concluded that an increase in $\mathrm{MB}$ concentration in the CA/MB samples causes a decrease in the contact angle of the tested surfaces, i.e., a reduction from 115 to $52^{\circ}$. At the same time, an increase in $\mathrm{MB}$ concentration leads to an increase in the measured surface free energy, i.e., from 5 to $42 \mathrm{~mJ} \mathrm{~m}^{-2}$.

The effect of plasma modification on the surface wettability was also investigated. For the control sample (CA nanofibers) no visible changes were observed for processing times equal to 15 and $30 \mathrm{~s}$. Only the 60-s modification resulted in a decrease in the contact angle by about $5 \%$ (i.e., from 115 to $109^{\circ}$ ). For CA/MB nanofibers with $\mathrm{MB}$ concentrations equal to 2.5 and $5 \mathrm{mg} \mathrm{mL}^{-1}$, an improvement in the wettability of the surface was observed after plasma treatment. A decrease in the contact angle with a simultaneous increase in 
the surface energy compared to the control sample (i.e., not treated with plasma) was seen. In the case of nanofibers with $\mathrm{MB}$ concentration of $10 \mathrm{mg} \mathrm{mL}^{-1}$, the enhanced wettability was observed only for $15 \mathrm{~s}$ treatment time, i.e., from 52 to $47^{\circ}$. For modification times of 30 and $60 \mathrm{~s}$, recovery of hydrophobic properties was noticed (i.e., contact angles were 135 and $132^{\circ}$, respectively). The above-described phenomenon requires detailed studies.

\subsection{Physicochemical and Biocidal Properties of Electrospun Fibers}

The spectroscopic studies on methylene blue water solution and CA/MB nanofibers were shown in Figure 9. As can be seen in Figure 9a, the electrospun CA/MB nanofibers showed the absorption spectrum characteristic of MB (see Figure $9 b$ ). Two characteristic peaks at 607-612 and 663-664 nm were observed for CA/MB fibers and they are similar to those previously reported for aqueous $\mathrm{MB}$ solution [38]. The macroscopic image of the electrospun CA and CA/MB nanofibers was presented in the inset in Figure 9c. The formation of $\mathrm{CA} / \mathrm{MB}$ nanofibers was indicated by the blue color of the obtained material.

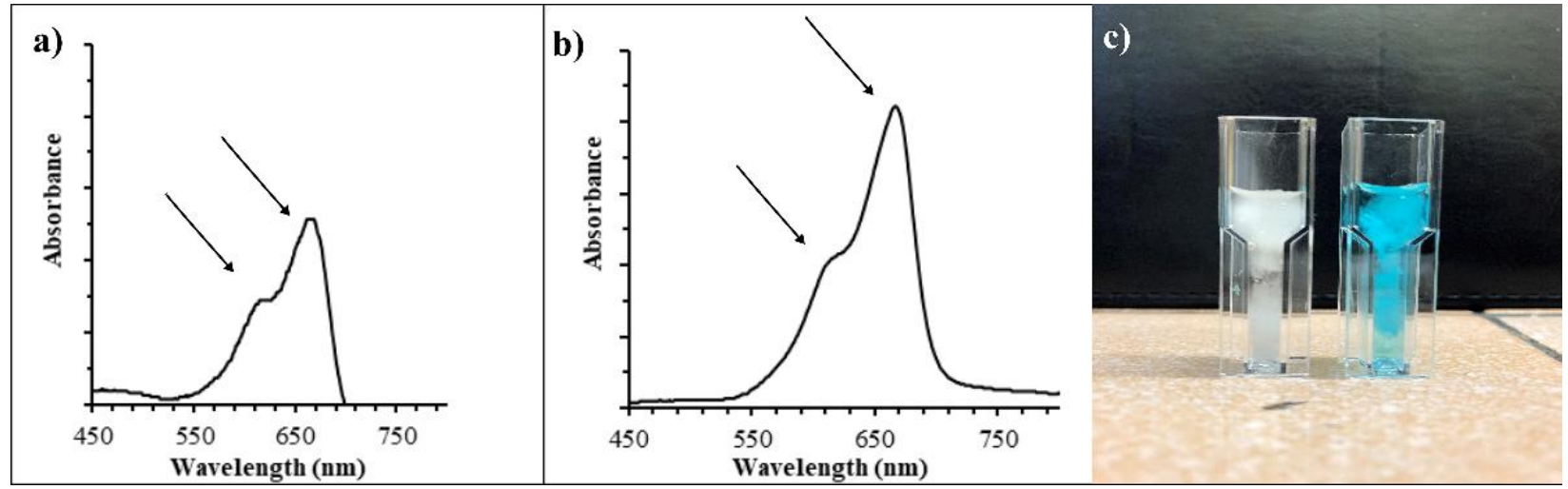

Figure 9. Absorbance spectrum of electrospun $\mathrm{CA} / \mathrm{MB}$ nanofibers (a) and water solution of $\mathrm{MB}(\mathbf{b})$. The macroscopic image (c) of the electrospun CA (left) and CA/MB nanofibers (right). Results were obtained for the polymer concentration equal to $17 \%$.

The FTIR spectrum of the pure cellulose acetate (blue line) shows the presence of three important vibrations at $1741 \mathrm{~cm}^{-1}, 1367 \mathrm{~cm}^{-1}, 1226 \mathrm{~cm}^{-1}$, and $1039 \mathrm{~cm}^{-1}$ (Figure 10). These peaks were assigned to $\mathrm{C}=\mathrm{O}$ stretching of the acetyl groups, $(\mathrm{C}-\mathrm{H})$ bending vibration of $\mathrm{CH}_{3}$ in the acetyl group, $(\mathrm{C}-\mathrm{O})$ stretching of the acetyl group, and $(\mathrm{C}-\mathrm{O}-\mathrm{C})$ of the cellulose backbone, respectively [39]. FT-IR spectrum of the CA/MB fibers (red line) showed that the intensity of peaks at $1741 \mathrm{~cm}^{-1}, 1367 \mathrm{~cm}^{-1}, 1226 \mathrm{~cm}^{-1}$, and $1039 \mathrm{~cm}^{-1}$ increased. Both spectra show broad intense bands that appear in the range of $2900-2950 \mathrm{~cm}^{-1}$ result from C-H stretching of $\mathrm{CH}_{2}$ or $\mathrm{CH}_{3}$ [40].

Moreover, a blue shift of $1741 \mathrm{~cm}^{-1}, 1367 \mathrm{~cm}^{-1}, 1226 \mathrm{~cm}^{-1}$ peak values were noted, which indicated the existence of physical interaction between CA and the dyestuff [41]. Significant shifting of the peak at $1039 \mathrm{~cm}^{-1}$ to $1027 \mathrm{~cm}^{-1}$ can be observed in the fibers containing MB. These shifts may be caused by direct deformation of the molecular backbone bonds, such as $\mathrm{C}-\mathrm{O}-\mathrm{C}$, as a consequence of macroscopic deformation of the fibers (i.e., increased in the molecular deformation of cellulose chains along the fiber axis) [42].

Then, the obtained CA/MB nanofibers were treated with the non-thermal plasma and the changes in chemical structure was examined by FT-IR method. FT-IR spectra of the untreated $\mathrm{CA} / \mathrm{MB}$ electrospun nanofibers and $\mathrm{CA} / \mathrm{MB}$ exposed to the non-thermal plasma (black line) are presented in Figure 10. When comparing pristine CA/MB nanofibers characteristic signals with $\mathrm{CA} / \mathrm{MB}$ nanofibers after exposition to the plasma, changes in their intensities were observed. A decreased signal at $1741 \mathrm{~cm}^{-1}, 1367 \mathrm{~cm}^{-1}, 1226 \mathrm{~cm}^{-1}$, and $1027 \mathrm{~cm}^{-1}$ after plasma treatment was noted. 


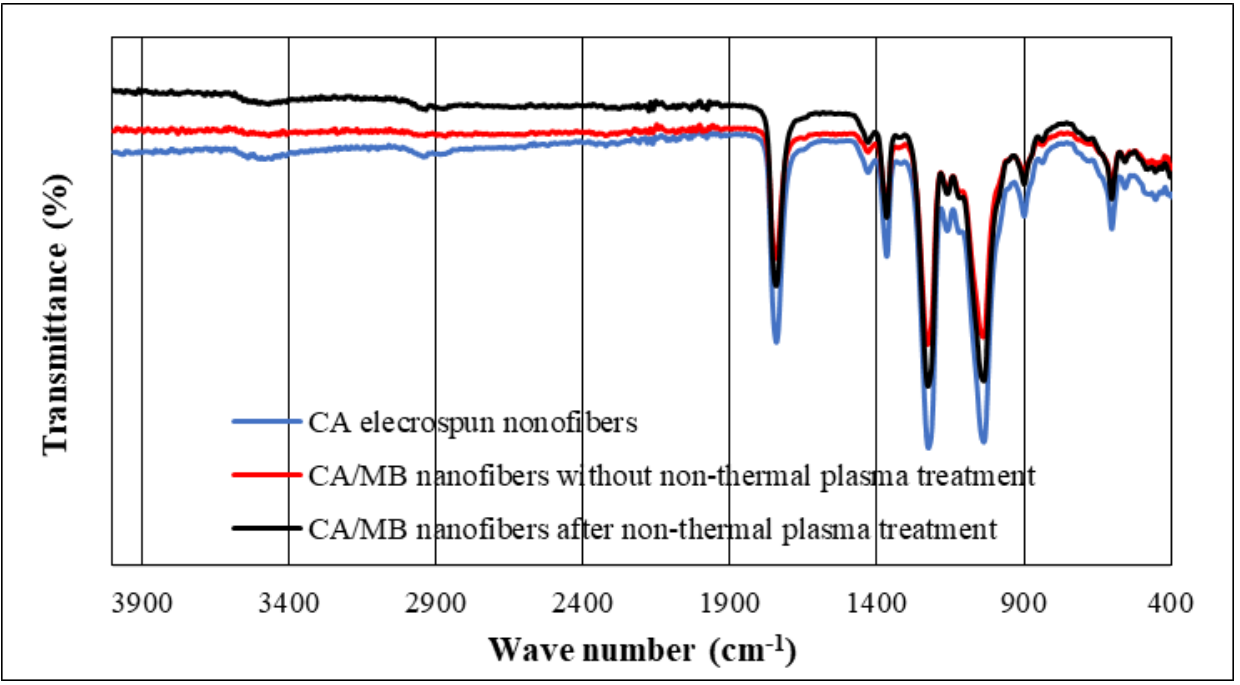

Figure 10. FT-IR spectra of pure cellulose acetate (CA) (blue line) and cellulose acetate + methylene blue; (CA/MB) nanofibers without non-thermal plasma treatment (red line); $(\mathrm{CA} / \mathrm{MB})$ nanofibers after non-thermal plasma treatment (black line). Results were obtained for the polymer concentration equal to $17 \%$.

In the next step of our experiments, the $\mathrm{CA} / \mathrm{MB}$ nanofibers without non-thermal plasma treatment (i.e., pristine) and after exposure to plasma were placed in the suspensions of $S$. aureus to study the efficiency of biofilm formation on their surface. As can be seen in Figure 11, bacterial biofilm was formed on the surface of the plasma-treated electrospun nanofibers as well as on the surface of the fibers without plasma exposure. The biofilm formation efficiency was higher on the surface of the untreated (pristine) $\mathrm{CA} / \mathrm{MB}$ fibers and it has been estimated that the biofilm formed on this surface contained $1.585 \times 10^{8}$ cells mg $^{-1}$ nanofibers. For comparison, on the surface of the electrospun fibers that were treated with the non-thermal plasma, the formed biofilm consisted of $1.25 \times 10^{6} \mathrm{cells} \mathrm{m}^{-1}$ nanofibers.

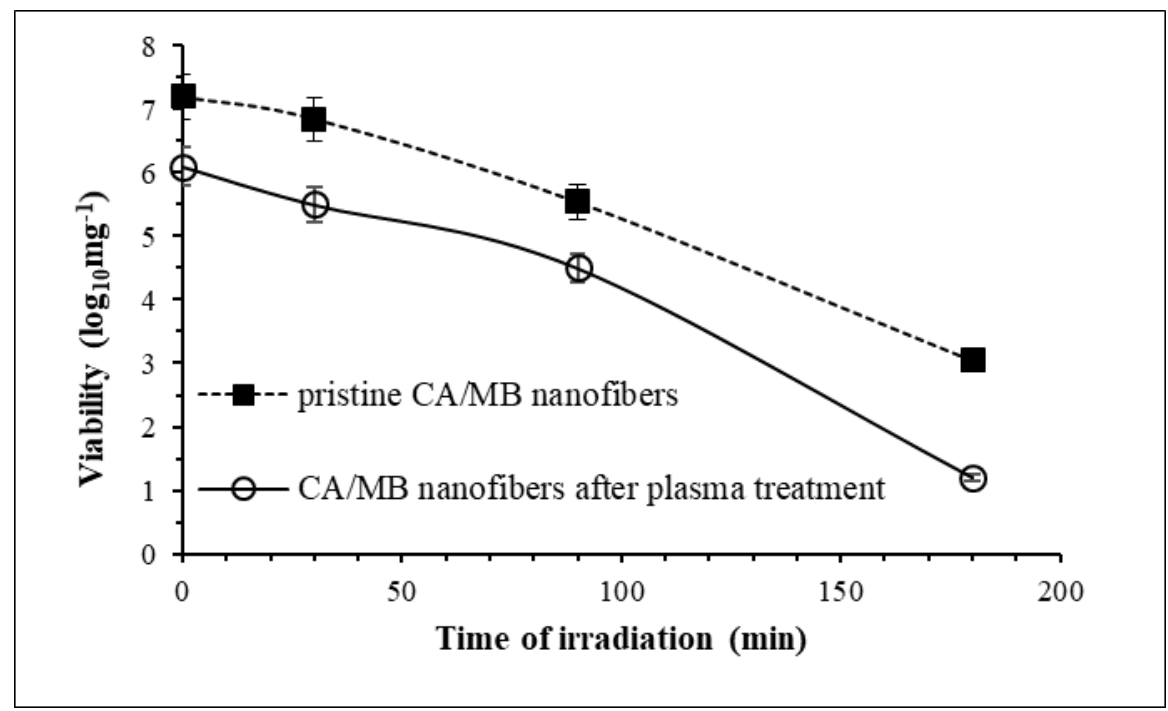

Figure 11. Time-dependent photo-bactericidal effect of electrospun CA/MB fibers on biofilm of $S$. aureus. Average $\pm \mathrm{SD}$ of three independent experiments are shown. The efficiency of this treatment was considered statistically significant for all groups $(p<0.05)$.

The efficiencies of biofilm formation on the surface of the untreated (i.e., pristine) $\mathrm{CA} / \mathrm{MB}$ nanofibers and the $\mathrm{CA} / \mathrm{MB}$ fibers after plasma treatment were confirmed using the SEM technique. As shown in Figure 12 (a-h micrographs), Staphylococcus aureus formed 
a biofilm on the surface of both CA/MB nanofiber samples. This biofilm is characterized by a large amount of extracellular matrix, which protects the bacteria cells against the harmful effects of external factors (for example antibiotics). Moreover, it is seen that the biofilm formed on the surface of the CA/MB nanofibers treated with the plasma is thinner and it seems that a smaller number of bacteria formed this structure (Figure 12a-d).

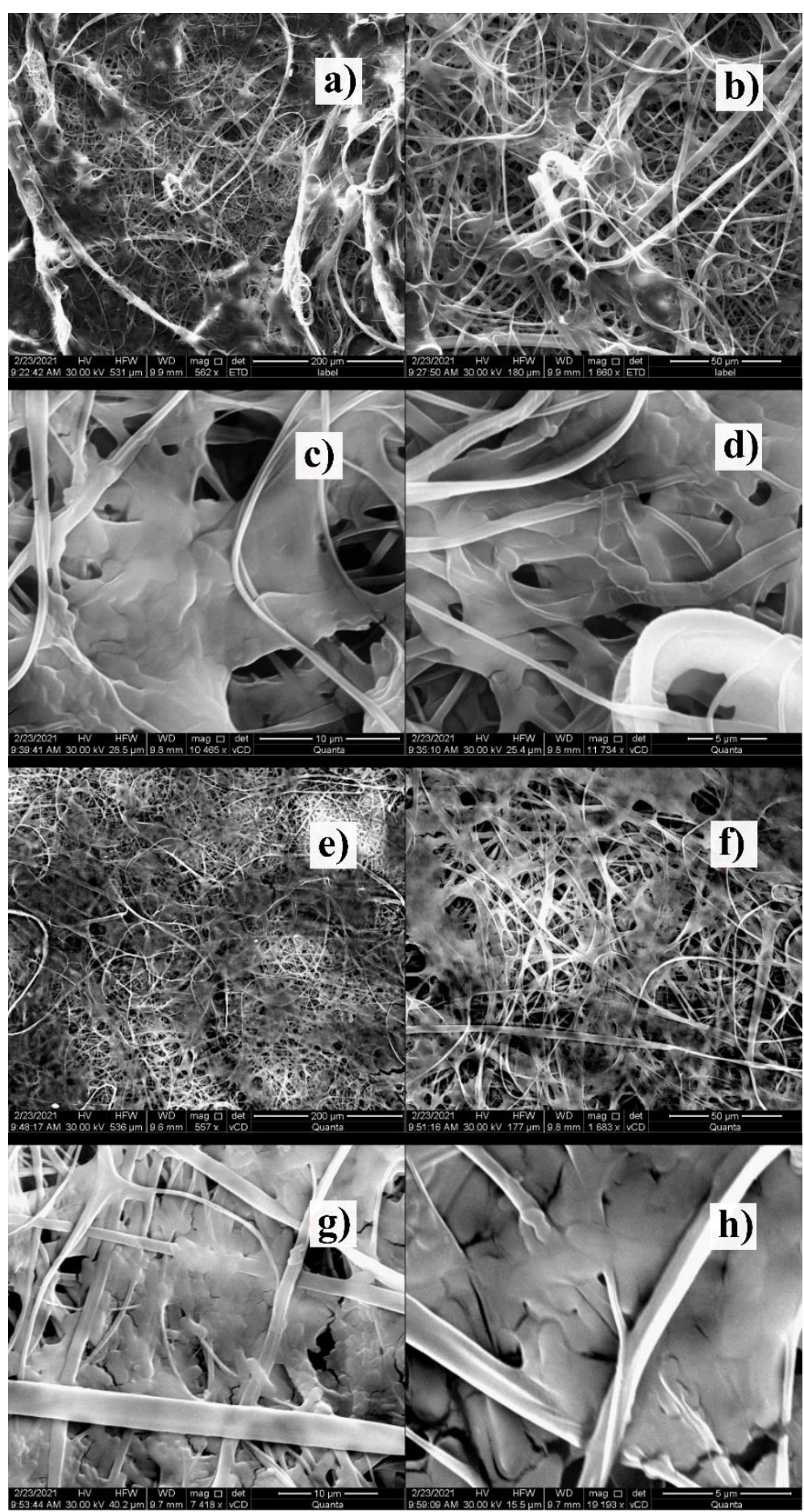

Figure 12. SEM micrographs of $S$. aureus biofilm formed on the surface of CA/MB electrospun nanofibers: treated with non-thermal plasma for $15 \mathrm{~s}(\mathbf{a}-\mathbf{d})$; without plasma treatment $(\mathbf{e}-\mathbf{h})$.

Next, the effect of light dose on the photo-eradication of biofilm cultures of $S$. aureus formed on the surface of electrospun CA/MB nanofibers was determined. The obtained 
results were presented in Figure 11. When untreated CA/MB fibers were irradiated using a neon tube (see Photodynamic inactivation of biofilm formed by S. aureus) the number of biofilm S. aureus cells was reduced by $95.58 \pm 0.2 \%$ (a reduction in CFU of $0.35 \log _{10}$ ), $97.81 \pm 0.2 \%$ (a reduction in CFU of $1.66 \log _{10}$ ), and $99.99 \pm 0.3 \%$ (a reduction in CFU of $\left.4.16 \log _{10}\right)$ after 30,90 and 180 min of irradiation, respectively $(p<0.05)$.

A light dose-dependent reductions of viability in biofilm cells by $74.7 \pm 0.2 \%$ (a reduction in CFU of $0.6 \log _{10}$ ), $97.47 \pm 0.2 \%$ (a reduction in CFU of $1.6 \log _{10}$ ), and $99.987 \pm 0.2 \%$ (a reduction in CFU of $4.9 \log _{10}$ ) were observed corresponding to 30, 90 and $180 \mathrm{~min}$ of irradiation when $\mathrm{CA} / \mathrm{MB}$ fibers after non-thermal plasma treatment were used in experiments (Figure 12).

\section{Discussion}

Bacterial fouling not only transfers infections and diseases from one surface to another and to humans, but also reduces the functionality, durability, and performance of various surfaces and devices. For example, nosocomial infections arise or may be caused by crosscontamination of surgical instruments, medical implants, and surfaces in the healthcare environment [43]. An ideal coating for several medical devices is a surface that resists bacterial adhesion and removes contaminations as they occur. Several antimicrobial materials containing various chemicals as coatings (e.g., antibiotics, salicylic acid, chlorhexidine, or quaternary ammonium compounds) have been described in the literature [44]. In the case of electrospun CA fibers, it was shown that CA/silver-sulfadiazine nanofibers [11] and $\mathrm{CA} /$ gelatin/hydroxyapatite were antimicrobial materials [12].

This paper describes electrospun fibers, which constitute a material that is difficult to colonize by bacteria (S. aureus) and these fibers produce cytotoxic reactive oxygen species (ROS) locally upon light irradiation to induce death of this pathogen in a timecontrolled manner.

This antimicrobial surface of CA fibers was obtained by combining two techniques. First, methylene blue was implemented into the polymer solution with a CA concentration of $17 \%$ to obtain fibers with photo-bactericidal properties. It should be noted that the obtained $\mathrm{CA} / \mathrm{MB}$ material was characterized by a decrease in the contact angle of the surface and an increase in the measured surface free energy compared to CA fibers, which resulted in less efficient adhesion of bacterial cells (data not shown).

Generally, electrospun fibers have several properties important to the photodynamic inactivation of microbes, including a large surface area that allows for enhanced photosensitizer/pathogen interaction. The electrospinning also allows the deposition of photosensitizers without the need to functionalize them [45-47]. This action enables the deposition of various photosensitizers, regardless of their chemical structure (size, functional groups) or physicochemical properties (charge). In addition, since the polymer and photosensitizer are combined in solution before electrospinning, there is minimal material homogeneity change [8].

The idea of the electrospinning process seems to be quite simple. In fact, the process is very complex due to the simultaneous occurrence of many physical phenomena. Additionally, the proper adjustment of process parameters provides nanofiber fabrication with required properties (e.g., electrical, mechanical, and biological). The presented studies have confirmed that many important factors influence the electrospinning process. It is essential to choose the right parameters of the process, which will provide its stability and continuous operation.

The results of the electrical measurement elucidate the nanofiber fabrication and the effect of process conditions on the physical properties of the fibers, including shape and size (see physical and electrical properties of CA and CA/MB nanofibers). The electrospinning process is based on the stretching of a charged jet of polymer solution with specific physical properties. The concentration of the polymer in the solution affects both the viscosity and the surface tension of the liquid, which finally determines the quality of the conducted electrospinning process. At low polymer concentrations, the charged jet breaks up into fine 
droplets before reaching the collector. When the polymer concentration and viscosity are increased, continuous nanofibers can be formed. It should be noted that at concentrations exceeding a certain limit, the solution viscosity becomes too high, which disturbs the polymer solution flow through the capillary and the fibers may have many defects or the process could stop. It was also found that there was an optimal range of applied voltage for a specific polymer-solvent system. Moreover, the obtained current-voltage characteristics of the electrospinning process indicate that the solvent evaporated only partially during the measurements.

The next step to further improve the antimicrobial properties of $\mathrm{CA} / \mathrm{MB}$ fibers was surface modification with the non-thermal plasma. In recent decades, the surface treatment of polymers with non-thermal plasmas has been extensively studied [48] and it has become apparent that this approach holds promise for a wide range of different polymers [49,50]. Plasma modification of the surface makes it possible to change the surface properties of the polymer to obtain the desired properties. We found that 15-s plasma treatment of $\mathrm{CA} / \mathrm{MB}$ fibers further reduced the contact angle of the surface, which was important for biofilm formation.

Our strategy to study the antimicrobial properties of the surfaces was based on the incubation of the cells (S. aureus) with the electrospun photoactive fibers, formation biofilm on its surface followed by irradiation of pathogen with light with a wavelength between 400 and $700 \mathrm{~nm}$.

It was established that the formation of $S$. aureus biofilm is more effective on the surface of pristine $\mathrm{CA} / \mathrm{MB}$ nanofibers. These results suggest that there is a direct relationship between surface hydrophobicity and the formation of staphylococcal biofilm. The more hydrophobic nanofibers provided better surfaces for biofilm development. Our results on the efficiency of S. aureus biofilm formation on CA/MB electrospun fibers are consistent with the results of $\mathrm{Xu}$ et al. [51]. The authors reported that the conversion of a hydrophobic surface (polyurethane) to a more hydrophilic structure resulted in a reduced biofilm formation efficiency. In contrast, Lee et al. [52] showed that the efficiency of biofilm formation of $S$. aureus was higher on hydrophilic surfaces (glass and stainless steel) than on hydrophobic surfaces (polypropylene and polystyrene). A possible explanation for this discrepancy in the results may be related to the methodology used to determine hydrophobicity and quantification of biofilm and to surface roughness as an important factor in cell adhesion.

It should be noted that Maikranz et al. [53] studied the adhesion of S. aureus cells to hydrophilic and hydrophobic surfaces. The obtained results show that the adhesion of bacteria to both types of surfaces is mediated by thermally fluctuating cell wall macromolecules, that behave differently on each type of surface. It was demonstrated that many macromolecules are involved in cell adhesion on hydrophobic surfaces. On the other hand, on hydrophilic surfaces, only a few macromolecules adhere tightly to the surface.

The efficiency of the killing bacterial cells was very high and dependent on the duration of exposure to light (i.e., irradiation time). The most effective reduction in the number of $S$. aureus biofilm cells formed on the surface of untreated CA/MB nanofibers was observed $(99.99 \%$ mortality was found after $180 \mathrm{~min}$ of light irradiation. In the case of nanofibers exposed to the non-thermal plasma, the mortality rate was only slightly lower, i.e., $99.987 \%$. The American Society of Microbiology has decreed that there is a need to kill at least $99.9 \%$ of the pathogen cells for the technique to be considered as "antimicrobial".

Our results cannot be compared with other data due to the lack of such data in the available literature. The previously described methods of obtaining photoactive materials have shown that they can be obtained by introducing/complexing photosensitizers on or in fibers [54]. For example, the preparation of photodynamic materials from electrospun nanofibers of P(MMA-co-MAA) co-polymer that were doped with montmorillonite (MMT), and further functionalized with methylene blue was described by Wang et al. [55]. The obtained nanofibers showed 99.997\% (4.8 log units) and 97\% (1.8 log units) reduction in $\mathrm{CFUmL}^{-1}$ against Staphylococcus aureus and Escherichia coli, respectively, after visible light 
illumination (LED lamp, $30 \mathrm{~min}, 35 \pm 5 \mathrm{~mW} \mathrm{~cm}^{-2}$ ). Methylene blue has also been loaded onto keratin films to provide a long-term inhibition of Staphylococcus aureus, reaching a bacterial killing rate of $99.9 \%$ after 75 -min light activation [56]. It has also been shown that this dye reduces the viability of microorganisms in biofilms grown on discs of bovine dentin upon LED light activation [57]. Contreras et al. [58] reported on fibrous scaffolds that were electrospun polyesters (poly( $\varepsilon$-caprolactone) (PCL) or poly [(rac-lactide)-co-glycolide] (PLGA)) with encapsulated photosensitizer (methylene blue or erythrosine B). Exposure of PS-encapsulated PCL fibers to visible light successfully led to at least a $1 \log _{10}$ reduction in E. coli viability after $60 \mathrm{~min}$ of light exposure.

It must be emphasized that the fabricated very effective photo-bactericidal material is durable and cheap. Moreover, preliminary studies showed that only a small amount of methylene blue was released after incubation for hours in PBS at room temperature (see Supplementary Materials).

When the methylene fiber release experiment was conducted in sunlight (data not shown), the concentration of the released dye exceeded the limit of quantification. This phenomenon can be explained by the known photobleaching effect of methylene blue in the presence of sunlight [59]. These findings prove that the resulting biocidal material can be recognized as self-sterilizing and environmentally friendly.

\section{Conclusions}

In this study, the photo-biocidal electrospun nanofibers were discussed. The presented studies have confirmed that many important variables influence the electrospinning process. It is essential to find the proper parameters of the process, which will guarantee its stability and continuous operation.

Another important aspect of research on the electrospinning process is to determine its electrical properties. Unfortunately, this topic is often neglected but in many cases it can help understand the fabrication of nanofibers from a liquid polymer solution.

The presented research results show some possibilities for the development of innovative materials with self-sterilizing properties when illuminated with visible light, such as solar radiation (i.e., from the point of view of microbiological contamination). The small size of photoactive fibers (i.e., at the level of a few hundred nanometres) additionally gives new opportunities for their use. Moreover, plasma treatment can be used to develop materials with a surface covered by a limited (i.e., reduced) layer of bacterial cells, e.g., forming a biofilm.

Supplementary Materials: The following are available online at https://www.mdpi.com/article/ 10.3390/en14092598/s1, Table S1: Results of the in vitro release of methylene blue from the pristine $\mathrm{CA} / \mathrm{MB}$ nanofibers and $\mathrm{CA} / \mathrm{MB}$ nanofibers after plasma treatment for $15 \mathrm{~s}$.

Author Contributions: Conceptualization, T.C. and I.M.; methodology, T.C. and I.M.; validation, A.W., T.C., and I.M.; formal analysis, T.C. and I.M.; investigation, A.W., T.C. and I.M.; resources, T.C. and I.M.; writing—original draft preparation, T.C. and I.M.; writing-review and editing, A.W., T.C. and I.M.; visualization, A.W., T.C. and I.M.; supervision, T.C., I.M, and R.K. All authors have read and agreed to the published version of the manuscript.

Funding: This research received no external funding.

Institutional Review Board Statement: Not applicable.

Informed Consent Statement: Not applicable.

Data Availability Statement: Not applicable.

Acknowledgments: This work was partially financed by a statutory activity subsidy from the Polish Ministry of Science and Higher Education (PMSHE) for the Department of Electrical Engineering Fundamentals and Department of Organic and Medicinal Chemistry Wrocław University of Science and Technology.

Conflicts of Interest: The authors declare no conflict of interest. 


\section{References}

1. Das, S.; Tiwari, M.; Mondal, D.; Ranjan, B.; Dhermendra, S.; Tiwari, K. Growing tool-kit of photosensitizers for clinical and non-clinical applications. J. Mater. Chem. B 2020, 8, 10897-10940. [CrossRef]

2. Wang, C.; Wang, J.; Zeng, L.; Qiao, Z.; Liu, X.; Liu, H.; Zhang, J.; Ding, J. Fabrication of electrospun polymer nanofibers with diverse morphologies. Molecules 2019, 24, 834. [CrossRef]

3. Wojasiński, M.; Ciach, T. Production of nano- and microfibers from synthetic and natural polymers-Nanofibers technology. In Synthetic Nano- and Microfibers, 1st ed.; Martijn Wagterveld, R., Marijnissen, J.C.M., Gradoń, L., Moskal, A., Eds.; WETSUS European centre of excellence for sustainable water technology: Leeuvarden, The Netherlands, 2020; pp. 19-33. [CrossRef]

4. Zahmatkeshan, M.; Adel, M.; Bahrami, S.; Esmaeili, F.; Rezayat, S.M.; Saeedi, Y.; Mehravi, B.; Jameie, S.B.; Ashtari, K. Polymer based nanofibers: Preparation, fabrication, and applications. In Handbook of Nanofibers; Barhoum, A., Bechelany, M., Makhlouf, A., Eds.; Springer: Cham, Switzerland, 2018; pp. 1-47. [CrossRef]

5. Jiang, H.; Wang, L.; Zhu, K. Coaxial electrospinning for encapsulation and controlled release of fragile water-soluble bioactive agents. J. Control. Release 2014, 193, 296-303. [CrossRef]

6. de Faria, A.F.; Perreault, F.; Shaulsky, E.; Arias Chavez, L.H.; Elimelech, M. Antimicrobial Electrospun Biopolymer Nanofiber Mats Functionalized with Graphene Oxide-Silver Nanocomposites. ACS Appl. Mater. Interfaces 2015, 7, 12751-12759. [CrossRef] [PubMed]

7. Stanley, S.L.; Scholle, F.; Zhu, J.; Lu, Y.; Zhang, X.; Situ, X.; Ghiladi, R.A. Photosensitizer-Embedded Polyacrylonitrile Nanofibers as Antimicrobial Non-Woven Textile. Nanomaterials 2016, 6, 77. [CrossRef] [PubMed]

8. Stoll, K.R.; Scholle, F.; Zhu, J.; Zhang, X.; Ghiladi, R.A. BODIPY-Embedded Electrospun Materials in Antimicrobial Photodynamic Inactivation. Photochem. Photobiol. Sci. 2019, 18, 1923-1932. [CrossRef] [PubMed]

9. Mishra, R.K.; Mishra, P.; Verma, K.; Mondal, A.; Chaudhary, R.G.; Abolhasani, M.M.; Loganathan, S. Electrospinning production of nanofibrous membranes. Environ. Chem. Lett. 2019, 17, 767-800. [CrossRef]

10. Soares, R.M.D.; Siqueira, N.M.; Prabhakaram, M.P.; Ramakrishna, S. Electrospinning and electrospray of bio-based and natural polymers for biomaterials development. Mater. Sci. Eng. C 2018, 92, 969-982. [CrossRef]

11. Khan, M.Q.; Kharaghani, D.; Ullach, S.; Shahzad, A.; Saito, Y.; Yamamoto, T.; Ogasawara, H.; Kim, I.S. Fabrication of antibacterial electrospun cellulose acetate/ silver-sulfadiazine nanofibers composites for wound dressings applications. Polym. Test. 2019, 74, 39-44. [CrossRef]

12. Samadian, H.; Salehi, M.; Farzamfar, S.; Vaez, A.; Ehterami, A.; Sahrapeyma, H.; Goodarzi, A.; Ghorbani, S. In vitro and in vivo evaluation of electrospun cellulose acetate/gelatin/hydroxyapatite nanocomposite mats for wound dressing applications. Artif. Cells Nanomed. Biotechnol. 2019, 46, 964-974. [CrossRef]

13. de Oliveira, B.P.; Menezes Aguiar, C.; Cruz Câmara, A. Photodynamic therapy in combating the causative microorganisms from endodontic infections. Eur. J. Dent. 2014, 8, 424-430. [CrossRef] [PubMed]

14. Klepac-Ceraj, V.; Patel, N.; Song, X.; Holewa, C.; Patel, C.; Kent, R.; Amiji, M.M.; Soukos, N.S. Photodynamic effects of methylene blue-loaded polymeric nanoparticles on dental plaque bacteria. Lasers Surg. Med. 2011, 43, 600-606. [CrossRef]

15. Siddiqui, S.H.; Awan, K.H.; Javed, F. Bactericidal efficacy of photodynamic therapy against Enterococcus faecalis in infected root canals: A systematic literature review. Photodiagn. Photodyn. Ther. 2013, 10, 632-643. [CrossRef] [PubMed]

16. Gillman, P.K. CNS toxicity involving methylene blue: The exemplar for understanding and predicting drug interactions that precipitate serotonin toxicity. J. Psychopharmacol. 2010, 25, 429-436. [CrossRef]

17. World Health Organization. The Selection and Use of Essential Medicines: Report of the WHO Expert Committee on Selection and Use of Essential Medicines, 2019 (Including the 21st WHO Model List of Essential Medicines and the 7th WHO Model List of Essential Medicines for Children); World Health Organization: Geneva, Switzerland, 2019.

18. National Library of Medicine (NLM)/National Institutes of Health. Available online: https://pubchem.ncbi.nlm.nih.gov/ compound/Methylene-blue (accessed on 17 April 2021).

19. Dufay, M.; Jimenez, M.; Degoutin, S. Effect of Cold Plasma Treatment on Electrospun Nanofibers Properties: A Review. ACS Appl. Biol. Mater. 2020, 3, 4696-4716. [CrossRef]

20. Sivan, M.; Madheswaran, D.; Asadian, M.; Cools, P.; Thukkaram, M.; Van Der Voort, P.; Morent, R.; De Geyter, N.; Lukas, D. Plasma treatment effects on bulk properties of polycaprolactone nanofibrous mats fabricated by uncommon AC electrospinning: A comparative study. Surf. Coat. Technol. 2020, 399, 126203. [CrossRef]

21. Rezaei, F.; Nikiforov, A.; Morent, R.; De Geyter, N. Plasma Modification of Poly Lactic Acid Solutions to Generate High Quality Electrospun PLA Nanofibers. Sci. Rep. 2018, 8, 2241. [CrossRef]

22. Sagitha, P.; Reshmi, C.R.; Sundaran, S.P.; Sujith, A. Recent advances in post-modification strategies of polymeric electrospun membranes. Eur. Polym. J. 2018, 105, 227-249. [CrossRef]

23. Pavliňák, D.; Galmiz, O.; Pavliňáková, V.; Poláček, P.; Kelar, J.; Stupavská, M.; Černák, M. Application of dielectric barrier plasma treatment in the nanofiber processing. Mater. Today Commun. 2018, 16, 330-338. [CrossRef]

24. Jacobs, T.; Morent, R.; De Geyter, N.; Dubruel, P.; Leys, C. Plasma surface modification of biomedical polymers: Influence on cell-material interaction. Plasma Chem. Plasma Process. 2012, 32, 1039-1073. [CrossRef]

25. Petlin, D.G.; Tverdokhlebov, S.I.; Anissimov, Y.G. Plasma treatment as and efficient tool for controlled drug release from polymeric materials: A review. J. Control. Release 2017, 266, 57-74. [CrossRef] [PubMed] 
26. Vesel, A.; Mozetic, M. New developments in surface functionalization of polymers using controlled plasma treatments. J. Phys. D Appl. Phys. 2017, 50, 293001. [CrossRef]

27. Asadian, M.; Chan, K.V.; Norouzi, M.; Grande, S.; Cools, P.; Morent, R.; De Geyter, N. Fabrication and Plasma Modification of Nanofibrous Tissue Engineering Scaffolds. Nanomaterials 2020, 10, 119. [CrossRef]

28. Mozaffari, A.; Parvinzadeh Gashti, M.; Mirjalili, M.; Parsania, M. Argon and Argon-Oxygen Plasma Surface Modification of Gelatin Nanofibers for Tissue Engineering Applications. Membranes 2021, 11, 31. [CrossRef] [PubMed]

29. Esbah Tabaei, P.S.; Asadian, M.; Ghobeira, R.; Cools, P.; Thukkaram, M.; Derakhshandeh, P.G.; Abednatanzi, S.; Van Der Voort, P.; Verbeken, K.; Vercruysse, C.; et al. Combinatorial effects of coral addition and plasma treatment on the properties of chitosan/polyethylene oxide nanofibers intended for bone tissue engineering. Carbohydr. Polym. 2021, 253, 117211. [CrossRef]

30. Afewerki, S.; Bassous, N.; Harb, S.V.; Corat, M.A.F.; Maharjan, S.; Ruiz-Esparza, G.U.; de Paula, M.M.M.; Webster, T.J.; Tim, C.R.; Viana, B.C.; et al. Engineering multifunctional bactericidal nanofibers for abdominal hernia repair. Commun. Biol. $2021,4,233$. [CrossRef] [PubMed]

31. Ojah, N.; Saikia, D.; Gogoi, D.; Baishya, P.; Ahmed, G.A.; Ramteke, A.; Choudhury, A.J. Surface modification of core-shell silk/PVA nanofibers by oxygen dielectric barrier discharge plasma: Studies of physico-chemical properties and drug release behaviour. Appl. Surf. Sci. 2019, 475, 219-229. [CrossRef]

32. Haertel, B.; von Woedtke, T.; Weltmann, K.D.; Lindequist, U. Non-thermal atmospheric-pressure plasma possible application in wound healing. Biomol. Ther. 2014, 22, 477-490. [CrossRef] [PubMed]

33. Feltz, K.P.; Growney Kalaf, E.A.; Chen, C.; Scott Martin, R.; Sell, S.A. A review of electrospinning manipulation techniques to direct fiber deposition and maximize pore size. Electrospinning 2017, 1, 46-61. [CrossRef]

34. Ibrahima, H.M.; Klingnerb, A. A review on electrospun polymeric nanofibers: Production parameters and potential applications. Polym. Test. 2020, 90, 106647. [CrossRef]

35. Islam, M.S.; Ang, B.C.; Andriyana, A.; Afifi, A.M. A review on fabrication of nanofibers via electrospinning and their applications. SN Appl. Sci. 2019, 1, 1248. [CrossRef]

36. Kim, S.C.; Kang, S.; Lee, H.; Kwak, D.B.; Ou, Q.; Pei, C.; Pui, D.Y. Nanofiber filter performance improvement: Nanofiber layer uniformity and branched nanofiber. Aerosol Air Qual. Res. 2020, 20, 80-88. [CrossRef]

37. Fahmy, A.; Zaid, H.; Ibrahim, M. Optimizing the electrospun parameters which affect the preparation of nanofibers. Biointerface Res. Appl. Chem. 2019, 9, 4463-4473. [CrossRef]

38. Yu, X.; Huang, L.; Wei, Y.; Zhang, J.; Zhao, Z.; Dai, W.; Yao, B. Controllable preparation, characterization and performance of $\mathrm{Cu}_{2} \mathrm{O}$ thin film and photocatalytic degradation of methylene blue using response surface methodology. Mater. Res. Bull. 2015, 64, 410-417. [CrossRef]

39. Fe, P.; Liao, L.; Cheng, B.; Song, J. Quantitative analysis of cellulose acetate with a high degree of substitution by FTIR and its application. Anal. Methods 2017, 9, 6194-6201. [CrossRef]

40. Salama, A.; Mohamed, A.; Aboamera, N.M.; Osman, T.; Khattab, A. Characterization and mechanical properties of cellulose acetate/carbon nanotube composite nanofibers. Adv. Polym. Technol. 2018, 37, 2446-2451. [CrossRef]

41. Dhananasekarana, S.; Palanivela, R.; Pappu, S. Adsorption of methylene blue, bromophenol blue, and coomassie brilliant blue by $\alpha$-chitin nanoparticles. J. Adv. Res. 2016, 7, 113-124. [CrossRef]

42. Wanasekara, N.D.; Michud, A.; Zhu, C.; Rahatekar, S.; Sixta, H.; Eichhorn, S.J. Deformation mechanisms in ionic liquid spun cellulose fibers. Polymer 2016, 99, 222-230. [CrossRef]

43. Boyce, J.M. Environmental contamination makes an important contribution to hospital infection. J. Hosp. Infect. 2007, 65, 50-54. [CrossRef]

44. Cassidy, S.S.; Sanders, D.J.; Wade, J.; Parkin, I.P.; Carmalt, C.J.; Smith, A.M.; Allan, E. Antimicrobial surfaces: A need for stewardship? PLoS Pathog. 2020, 16, e1008880. [CrossRef]

45. Kim, J.R.; Michielsen, S. Photodynamic activity of nanostructured fabrics grafted with xanthene and thiazine dyes against opportunistic fungi. J. Photochem. Photobiol. B Biol. 2015, 150, 50-59. [CrossRef]

46. Henke, P.; Lang, K.; Kubát, P.; Sýkora, J.; Šlouf, M.; Mosinger, J. Polystyrene nanofiber materials modified with an externally bound porphyrin photosensitizer. ACS Appl. Mater. Interfaces 2013, 5, 3776-3783. [CrossRef] [PubMed]

47. Lhotáková, Y.; Plíštil, L.; Morávková, A.; Kubát, P.; Lang, K.; Forstová, J.; Mosinger, J. Virucidal nanofiber textiles based on photosensitized production of singlet oxygen. PLoS ONE 2012, 7, e49226. [CrossRef] [PubMed]

48. Morent, R.; De Geyter, N.; Desmet, T.; Dubruel, P.; Leys, C. Plasma surface modification of biodegradable polymers: A review. Plasma Process. Polym. 2011, 8, 171-190. [CrossRef]

49. Desmet, T.; Morent, R.; De Geyter, N.; Leys, C.; Schacht, E.; Dubruel, P. Nonthermal plasma technology as a versatile strategy for polymeric biomaterials surface modification: A review. Biomacromolecules 2009, 10, 2351-2378. [CrossRef]

50. Chu, P.K.; Chen, J.Y.; Wang, L.P.; Huang, N. Plasma-surface modification of biomaterials. Mater. Sci. Eng. 2002, 36, 143-206. [CrossRef]

51. Xu, L.C.; Siedlecki, C.A. Submicron-textured biomaterial surface reduces staphylococcal bacterial adhesion and biofilm formation. Acta Biomater. 2012, 8, 72-81. [CrossRef]

52. Lee, J.S.; Bae, Y.M.; Lee, S.Y.; Lee, S.Y. Biofilm Formation of Staphylococcus aureus on Various Surfaces and Their Resistance to Chlorine Sanitizer. J. Food Sci. 2015, 80, M2279-M2286. [CrossRef] [PubMed] 
53. Maikranz, E.; Spengler, C.; Thewes, N.; Thewes, A.; Nolle, F.; Jung, P.; Bischoff, M.; Santen, L.; Jacobs, K. Different binding mechanisms of Staphylococcus aureus to hydrophobic and hydrophilic surfaces. Nanoscale 2020, 12, 19267-19275. [CrossRef]

54. Wang, J.; Zhu, Y.; Bawa, H.K.; Ng, G.; Wu, Y.; Libera, M.; van der Mei, H.C.; Busscher, H.J.; Yu, X. Oxygen-generating nanofiber cell scaffolds with antimicrobial properties. ACS Appl. Mater. Interfaces 2010, 3, 67-73. [CrossRef]

55. Wang, Q.; Chen, W.; Zhang, Q.; Ghiladi, R.A.; Wei, Q. Preparation of photodynamic P(MMA-co-MAA) composite nanofibers doped with MMT: A facile method for increasing antimicrobial efficiency. Appl. Surf. Sci. 2018, 457, 247-255. [CrossRef]

56. Aluigi, A.; Sotgiu, G.; Torreggiani, A.; Guerrini, A.; Orlandi, V.T.; Corticelli, F.; Varchi, G. Methylene blue doped films of wool keratin with antimicrobial photodynamic activity. ACS Appl. Mater. Interfaces 2015, 7, 17416-17424. [CrossRef] [PubMed]

57. Cusicanqui Méndez, D.A.; Gutierrez, E.; Dionísio, E.J.; Oliveira, T.M.; Rabelo Buzalaf, M.A.; Rios, D.; Moreira Machado, M.A.A.; Cruvinel, T. Effect of methylene blue-mediated antimicrobial photodynamic therapy on dentin caries microcosms. Lasers Med. Sci. 2018, 33, 479-487. [CrossRef]

58. Contreras, A.; Raxworthy, M.J.; Wood, S.; Schiffman, J.D.; Tronci, G. Photodynamically active electrospun fibers for antibiotic-free infection control. ACS Appl. Bio Mater. 2019, 2, 4258-4270. [CrossRef]

59. Demchenko, A.P. Photobleaching of organic fluorophores: Quantitative characterization, mechanisms, protection. Methods Appl. Fluoresc. 2020, 8, 022001. [CrossRef] 